\title{
On the Benefits and Burdens of the Notion of "Standpoint”
}

\author{
Koichiro Misawa \\ Tokyo University of Social Welfare
}

\begin{abstract}
Despite the widespread endorsing of multiculturalism, the progress of enquiry into it and multicultural education have been impeded by a suspicion of cultural relativism and intellectual insularity. This paper reveals that such a suspicion is spurious by paying special attention to the notion of "standpoint” which has a relative but substantial effect. The proper recognition of this point highlights the sense in which the insights drawn from multiculturalism and their educational embodiments are crucial for the future of humanity as a whole, which is far beyond the enduring controversy about universality and particularity.
\end{abstract}

Keywords: multiculturalism, standpoint, universalism, relativism, unitary epistemology

\section{Introduction: A Point of Departure for Discussing Multiculturalism}

Today paying tribute to multiculturalism is almost an essential prerequisite of any kind of philosophical study of education. Such a tendency is easily found even in the discourse putting premium on "truth-values" in education (e.g., Goldman 1998). The widespread endorsing of multiculturalism among many philosophers (of education), however, seems due more to a "morally and politically correct" attitude than to philosophical reasons. ${ }^{1}$ This sits happily with the view that multiculturalism is to be understood as "primarily a moral and/or social/political matter, rather than an epistemological one” (Siegel 2007, 217). Perhaps two major obstacles to a further philosophical reflection on multiculturalism and its educational embodiments are, as some specialists in multicultural education say, "a degree of cultural relativism" (Dhillon \& Halstead 2003, 154) “(the multicultural education literature's) intellectual insularity and limited conceptual tools” (Fullinwider 2003, 498).

There may seem little prospect of further illumination on the matter of multiculturalism. Yet, this is not a legitimate judgement. Multiculturalism, in my view, should come under the scope of more detailed philosophical discourse inasmuch as it has a number of philosophically relevant and educationally imperative issues that are more than a complement. The aim of this paper is therefore to add a significant nuance to discussions of multiculturalism with the suggestion that multiculturalism has value not only for educational ideals but also for philosophical reflection (especially on the nagging issue of universality and particularity). I will endeavor to do so by consideration of the notion of "standpoint" that is one of the keys to exploring the themes of multiculturalism and multicultural education.

Where to begin enquiry is perhaps the most difficult part in addressing the notion of standpoint because there is no standpoint that is free of social, cultural, historical particularities and contingencies. So it might be wise to begin by looking at the discourse which puts enormous emphasis on transcultural universality, but not at

Koichiro Misawa, Ph.D. in Philosophy of Education, lecturer, School of Education, Tokyo University of Social Welfare, Japan; main research fields: Philosophy of Education and Mind, and Issues in Epistemology. Email: fmmt21nm@gmail.com. 
the expense of multiculturalism. For this purpose, hardly anyone's argument would be more appropriate than that of Harvey Siegel's to the extent that he vigorously provides a philosophical underpinning for the defence of “Western, 'Enlightenment’ Thought” (Siegel 1999, 402) in relation to educational values and ideals. ${ }^{2}$ Siegel’s conception of multiculturalism is that "multiculturalism is itself culturally transcendent or universal moral, educational and social ideal in the sense that it is applicable to all cultures, even those which do not recognize or embrace it” (Siegel 1999, 397). It seems hard to deny that this view of Siegel is, albeit in sympathy with multiculturalism, often taken as a defence of an Enlightenment-inspired transcendental argument and thereby has provoked a number of reactions and criticisms. I do not object to the thesis that there are universal knowledge claims and multiculturalism is one such. The logical and formalistic arguments for something universal like Siegel's, however, tend to shed little light on the notion of "standpoint," with the assumption that it has little effect on those logical arguments. As far as the argument goes at a formal level, this assumption is probably right. ${ }^{3}$ But, at the same time, it is also uncontentious that standpoints one takes have an unavoidable and sometimes unintended effect on our real lives. The question to be posed, then, is how the following questions might affect what we count as universal knowledge claims and, more generally, affect our contentful lives: For example, "whose justice, which rationality?" (Alasdair MacIntyre) and "whose science? whose knowledge?” (Sandra Harding). I shall, in what follows, engage in argument of “epistemological” assumptions lurking behind moral issues in multiculturalism and multicultural education.

Apparently, there is a binary opposition. On the one hand, what makes the post-Enlightenment view look plausible is the standards of the Enlightenment; on the other, the quasi-universality of the Enlightenment view turns on shaky grounds. I think this formulation of the issue blinds us to the need for a greater sensitivity in discussions of multiculturalism. In other words, they could be rendered compatible with each other without undermining their respective major insights, which demands a serious reframing of the old debate about universalism and relativism, and universality and particularity.

Seeing the points Siegel makes with regard to the issues germane to the notion of standpoint as a useful departure for a further enquiry, this paper reaches the conclusion that standpoint has a relative but substantial effect. This conclusion may be greeted with the complaint that it is too modest. However, the attraction of the view I will elaborate below is that it saves room for the delicate complexity that has gone unaddressed in the enduring controversy between the universalist and the particularist. Another benefit of pursuing the relevant sensitivity is to raise awareness of the recognition that there is a multiplicity of issues in discussions of multiculturalism which are concerned with recurring motifs in the mainstream of philosophical discourse. This is to imply the importance of education in the widest sense for a future of humanity.

\section{A Defence of Western, Modernist, and Enlightenment Epistemology: The Case of Harvey Siegel}

Of contemporary philosophers talking about questions of education, Harvey Siegel is conspicuous to the extent that he forcefully vindicates the validity of "Western, Modernist, Enlightenment epistemology" (Siegel 1997, 142) and its value for education from recurring challenges towards it. He defends his position from many "post-analytical” challenges that mark the recent philosophy of education discourse: e.g., post-modernist views, (neo-) pragmatism, arguments for "epistemological diversity” exemplified by feminist epistemology, social epistemology, and multiculturalism. Siegel renounces these new challenges to the Enlightenment philosophical tradition insofar as they more or less intimate that the central constituents of traditional epistemology—abstract 
rationality, theoretical justification, infallible certainty, theoretical reason, objective knowledge, absolute truth, the a priori, conceptual clarification, immediate universality, and so on-have lost much of their force. He is certainly not an uncompromising defender of all the components of traditional epistemology as he rules out “infallible certainty." Still, there is no doubt that, in Siegel's view, traditional epistemology is, mutatis mutandis, the starting point of our philosophical enquiry into knowledge and education. In this regard, what he advocates can be seen as traditional epistemology with fallibilism. ${ }^{4}$ Put simply, Siegel's discourse grounds itself on the discussions that demonstrate the validity of rationality, individualist epistemology, and universally applicable arguments.

Armed with this kind of traditional epistemology with fallibilism, Siegel describes one significant aim of education, among other things, as follows:

it is educationally important that students gain knowledge, and the ability to engage in rational enquiry; and that students develop an appreciation of such enquiry, and (insofar as they are able) conduct their believing, judging and acting accordingly. That is, students should be led, in their education, to value enquiry, and the justification that the evidence thereby produced offers to candidate beliefs, judgements and actions. (Siegel 1998, 20, italics in original)

I have no quarrel with Siegel's manifestation, as long as such an aim is formally expressed. However, I think it might not be totally unreasonable to ask what the formal expression may look like, when some concrete contents are given to it substantively. In other words, it may be worth exploring how far Siegel's view takes a substantial account of the interpenetrating relation between form and matter. ${ }^{5}$ This point is in need of further explanation and clarification.

Siegel puts the above view forward by highlighting the importance of "critical thinking" which he sees as "the educational cognate" of rationality ${ }^{6}$ (Siegel 1988, 127), on the following four grounds: "morality and respect for persons, self-sufficiency and preparation for adulthood, initiation into the rational traditions, and the requirements of democratic living" (61). He argues that some critical spirit in critical thinking is, like the ideal of multiculturalism, "fully generalizable" (Siegel 1997, 37), at least in theory, and goes so far as to say that: "particular ideals-in my case, critical thinking —are in fact applicable to all societies and the people within them, whether or not those ideals are in fact endorsed by particular societies or their members." (Siegel 2008, 182, italics added)

This contention is premised on Siegel's general views which are "firmly based on the 'Enlightenment' philosophical tradition, and [which] aspire to establish univocal analyses of rationality and of the educational ideal of critical thinking - analyses which pay scant attention to the differences among the 'concrete others' who are our students (and ourselves)" (Siegel 1997, 7, italics added). It may well be that this argument of Siege's invites the challenges from the perspectives that center on such "differences" to which Siegel pays only "scant" attention.

\section{3. "Standpoint Epistemology" and "Unitary Epistemology"}

Looking at the classification made by Siegel himself helps to explore this issue. Critical thinking, he avers, has (at least) two central components: (i) "a reason assessment component, which involves abilities and skills relevant to the proper understanding and assessment of reasons, claims and arguments;" and (ii) "a critical spirit component, which is understood as a complex of dispositions, attitudes, habits of mind, and character traits” (Siegel 1997, 27, italics in original). According to Siegel's account, his opponents have devoted exclusive attention to (i) — the issue of reason assessment—and claimed that skills, principles, and criteria of 
reason assessment differ from one standpoint (case, domain, subject, society, culture, and the like) to another and thus that the generalization of them is a lost cause.

The way Siegel disputes such claims deserves mention. The reason assessment component, Siegel explains, can further be divided into two kinds of sphere: One is subject-specific, but the other is a "fully generalizable" terrain which Siegel calls "the epistemology underlying critical thinking” (Siegel 1997, 28). He adduces some examples of the criteria which constitute such an underlying unitary epistemology and extend across subjects: “criteria of deductive validity, inductive strength, observational adequacy and explanatory power” (Siegel 1997, 36).

With regard to (ii) — the matter of critical spirit—, Siegel holds that the critical spirit is fully generalizable, notwithstanding the fact that its generalizability has been little discussed. The exemplars of critical spirit he refers to are: open-mindedness, fair-mindedness, non-question-begging evaluation, openness to objections and alternative points of view, habits of reason seeking and evaluating, a rejection of partiality, arbitrariness, special pleading, wishful thinking as well as of other obstacles to the proper exercise of reason assessment and reasoned judgement, and so on (Siegel 1997, 35; Siegel 2006, 5, 9). These, Siegel argues, are all Enlightenment modes of principles.

Setting aside (ii)—critical spirit—for the time being, I focus on (i)—reason assessment—and then proceed to (ii) with insights gained from a close analysis of (i). The thrust of the challenge towards Siegel's Enlightenment-based position—let us call it "standpoint epistemology" for expediency's sake — — runs broadly as follows: that knowledge from " $S$-knows-that- $p$ epistemology" (i.e., traditional epistemology) reflects privileges; advances the interests of culturally dominant groups (like men); marginalizes and oppresses members of non-dominant groups (like women); and therefore that accounts of knowledge must take subjectivity into account to overcome this problem (Siegel 2003, 308; Siegel 1998, 24). ${ }^{8}$ It would be of use here to make comparison with what he dubs “epistemological subject diversity,” which is something like:

the idea that different fields utilize different, incompatible criteria for the determination of the goodness of reasons, so that what counts as a good reason in one field does not so count in another, and therefore that principles and skills of reason assessment must differ from field to field and so be taught in the context of the subject matter of each field. (Siegel 1997, 29, italics added).

If standpoint epistemology is merely a variant of this kind of relativistic idea, there is no hope of vindicating it. Speaking transcendentally across different standpoints from within one particular standpoint betrays their own doctrine that one cannot correctly understand another standpoint from a specific standpoint. If one standpoint is utterly impervious to, and incommensurable with, another, we cannot even say anything like the standpoint epistemologist's contention. We need a means by which a standpoint is taken to be different from another standpoint. Siegel terms this shared criterion a "unitary epistemology" which is universal in character (Siegel 1997, 34).

As just noted, if "standpoint epistemology" is the thesis that does not admit such an underlying common epistemology, we ipso facto have to repudiate it. In this respect, there is nothing inconsistent with Siegel's argument that it is not until we rely, consciously or unconsciously, on an underlying unitary epistemology that the insistence of "standpoint epistemology" obtains at all. Siegel warns us against a confusion of "epistemology" with "a point of view."

To say that we... have two different epistemologies at work ... is to fail to distinguish between different epistemologies, and 
different criteria of reason assessment. When we have two different criteria of reason assessment, which we utilize to establish two different sorts of claims, we nevertheless have only one epistemology. In both cases, a good reason is that which warrants a conclusion. The epistemology across these alternative and varied criteria of reason assessment are the same. (Siegel 1997, 32, italics in original)

What he repeatedly tries to bring out is due attention to the underlying unitary epistemology that lies beneath all such variations. I agree with Siegel that it is necessary to be open-eyed about what enables us to identify difference as difference across the contextual borders and be alert to the seductive appeal of sheer relativism. But I suspect it is fair to wonder how far Siegel's formalistic argument for multiculturalism with the ambit of a rigorous defence of something universal enriches the contemporary debate about multiculturalism and its educational embodiments. For, it sometimes seems that Siegel simplifies the issue by having always been concerned to characterize only a necessary but not a sufficient condition for elaborating discussions of multiculturalism. That is to say, Siegel's assertion about the generalizability of the underlying unitary epistemology may leave open the question whether it lacks a substantial account of the "contentful" effects that the notion of standpoint can exert. ${ }^{9}$

\section{The Effect of Standpoint}

In this section, thus, I demonstrate that the idea of "standpoint" is not entirely empty and thereby that the insistence that there is a context-independent formal framework by which difference can be identified as difference is never the last word on the issue in question. Attention to what may be left out of Siegel's well-established line of argument amplifies the critical potential of the notion of standpoint in particular and multiculturalism more generally. The beginning of wisdom in gaining a profound insight in the literature of multiculturalism is, I think, the proper recognition that we human beings can understand another standpoint from a different standpoint to a considerable degree, if we have enough motivation and imagination to learn it. To throw light on this point, I will borrow an imaginary but telling example from Terry Eagleton.

There is an obvious difference between recounting a fact, such as "This cathedral was built in 1612," and registering a value-judgement, such as "This cathedral is a magnificent specimen of baroque architecture.” [sic] But suppose I made the first kind of statement while showing an overseas visitor around England, and found that it puzzled her considerably. Why, she might ask, do you keep telling me the dates of the foundation of all these buildings? Why this obsession with origins? In the society I live in, she might go on, we keep no record at all of such events: We classify our buildings instead according to whether they face north-west or south-east. (Eagleton 1983, 11)

Two points are to be fully appreciated: First, there is no room for sheer relativism; second, nevertheless, the first point is perfectly compatible with acknowledging that the difference in standpoints may alter our dealings with the object under consideration.

I begin with the first point. In this situation above, ordinary English people and the overseas visitor clearly take different points of view about the cathedral. It is also granted that this difference is due in large part to different kinds of social, cultural, and other contexts. But the crucial point here is that we-including myself (Japanese) — can no less understand a criterion of the visitor's culture than this visitor can understand the English criterion that values the chronological explanation. The recognition that different standpoints are, albeit in differing degrees, intelligible makes us aware that the real complication does not reside in the misconceived idea that different standpoints are incommensurable. But rather the complication is rooted in the plain fact that there are a huge number of standpoints that can be intelligible but most of which are little noticed because of 
the domination of a particular standpoint that acquires general currency due to a complex mix of social, political, economic, cultural, and various other factors. The proper lesson drawn here is: That a standpoint is universally intelligible does not assure us that it should be universally applied as the only standard; we should not confuse universal intelligibility with the "legitimacy" of universal applicability. ${ }^{10}$

I move onto the second point: The difference in standpoints may alter our perceiving and understanding of the object under consideration. It is of importance to resist the temptation to set up a false dichotomous relation between standpoint-relative and standpoint-transcendent spheres. To illustrate my point, I make use of the distinction between doxastic justification and propositional justification in epistemology which Siegel sometimes refers to, aware that we must be careful not to conflate the issue of (individual) understanding with that of unitary epistemology. ${ }^{11}$

According to his account, it is only doxastic justification that is subject to a "believer's context," namely, believer's epistemic conditions. On the other hand, propositional justification is transcendent in that "the status of any belief as propositionally justified does not depend upon the believer's view of its justificatory status, or of the belief being sanctioned by standards the believer (and/or her community) accepts;" that is, " $P$ can propositionally justify $q$ even if no one thinks it does" (Siegel 1997, 123, italics added). Deductive relations of statements are one emblematic exemplar of propositional justification. Siegel elucidates propositional justification as follows:

This sort of justification is independent of context, and involves strictly the epistemic status of, and relationships between, the relevant beliefs. Propositional justification (when put in terms of claims or propositions) is exactly "justification independent of reasoning agents" (When put in terms of beliefs, "believing agents" are required, since there can be no beliefs without believers... ). (Siegel 1997, 123, italics added)

I agree that, if not for the deductive relations between statements, virtually no linguistic and conceptual capacities of human beings would work in a coherent way. I also grant that there are extra-psychological objects and phenomena in the world. Yet, it is slightly misleading to suppose that there is a domain which is humanly context-dependent on the one hand and there is an extra-psychological sphere on the other. ${ }^{12}$ For what entities or relations become the possible objects of our knowledge are not built-in properties on the side of "the world as it really is.” This point seems in need of further clarification.

As noted earlier, Siegel adduces the following as constituting the common epistemology: deductive validity, inductive strength, observational adequacy, explanatory power, etc.. Certainly, deductive inference is valid across societies and epochs, even if the contents of premises in deductive reasoning are radically different from society to society. However, at the same time, it should be properly realized that what kinds of deductive and logical inference figure are "discovered" at least partly depend on what modes of society are run or on what lines of organized research are pursued. Put simply, whereas deductive and logical inference, once recognized, turns out to be valid across societies and epochs, it is particular humans and societies that "discover" or cast light on particular modes of deductive and logical inference.

For example, Fermat's Last Theorem is valid across societies and epochs. Now we can say that it had been valid even before Andrew Wiles's proof was published in 1995 and, in fact, even before this theorem was first predicted by Pierre de Fermat in 1637. Yet why this theory is conjectured at all by Fermat and why so many attempts to prove it have been made for more than 350 years are never independent of the way particular people in particular societies have lived (It is not difficult to imagine a world where Fermat's Last Theorem has not 
been proved, nor is it even a subject of focus at all. Similarly, it is not difficult to imagine a world where a countless number of theorems that do not see the light of day or even have not ever been conjectured in the present world figure). The conclusion to be drawn from these considerations echoes the point made above: That is, the universal intelligibility of a particular mode of deductive and logical inference is one thing and what kind of deductive and logical inference figures is another. These two different things cannot be adjudicated by deductive or logical inference. This thread of argument should be understood in a way consistent with the ideas that there are extra-psychological objects which are not human creations and that something extra-psychological like trees and stars exist as trees and stars only insofar as human beings attach such significance. We should therefore dissociate ourselves from the hard and fast distinction between mind and world.

When it comes to the other constituents of the underlying unitary epistemology Siegel refers to (in particular, observation and explanation), Siegel's formulation of the overarching unitary epistemology as transcending particularities needs more caution. For, again, even though the case for the neutrality of logical forms of criteria for inference is compellingly made, what qualifies as sufficient explanatory power, for example, might not coincide among different societies. Such a difference affects the way the world is for particular groups of human beings not in terms of its material structure but in terms of how they perceive and understand it. The example Martha Nussbaum mentions helps to encapsulate this point: Although most Americans are aware of the fact of religious difference, they may be unaware that difference encompasses what counts as worship itself and what a ritual of worship is. (Nussbaum 1997, 120)

It would be highly instructive here to draw attention back to what Siegel calls "critical spirit." I wholeheartedly embrace the components Siegel adduces, but this does not preclude the possibility that "difference encompasses what counts as critical spirit.” As long as what figures as critical spirit is, in a certain sense, deeply interwoven with the modes of life in which people are inescapably enmeshed, what Harding terms "systematic ignorance" (Harding 2000, 250) is likely to be unavoidable. This should not fall into oblivion in discussions of multiculturalism.

The implication of this line of argument is that the assumption of "all other things being equal" is of no real use. To revert to Eagleton's example, it would be nonsense to assume that the English standpoint and the visitor's standpoint differ only in terms of origins and emplacements of buildings. In other words, just as the priorities they give vis-à-vis a building are different, so it would be natural enough to suppose that their attitudes towards many aspects in their lives-e.g., in terms of what counts as objects for observation and what constitutes relevance of evidence for one issue-also differ with varying degrees and forms. There is, thus, a sense in which those differences may change how a building strikes an English person and the visitor.

I have urged that there is some room for the idea of "standpoint" that grows and alters in accordance with how particular groups of human beings develop their mode of life. However, "standpoint" is also not an all-encompassing notion. The key observation I want to bring out next is that a "standpoint" is defined only by arbitrary and relative interests and concerns.

\section{The Arbitrariness of Standpoint}

In whatever ways it may be formulated, the most serious theoretical problem of "standpoint epistemology"13 is this: It is impossible to neatly align every standpoint in a neutral line. It is a step forward to take into consideration various particular and contingent bounds from which no one can escape and which 
constitute and constrain people’s perspectives by dismissing "a view from nowhere" or "a God's eye view." Still, we should bear in mind that it is impossible to specify and disclose entangled factors which form a particular standpoint in a neutral line. Therefore, a perspective per se from which to debunk non-universal aspects of an allegedly universal or transcendental view is bound by a complex combination of such factors. In a nutshell, the thesis of "standpoint epistemology" does not make full sense unless and until all possible standpoints are known. Yet, there is no hope of making all possible standpoints lined up. ${ }^{14}$ Going along with an example of "standpoint epistemology" helps to illuminate this point.

Epistemology from a non-European point of view is an exemplar of such "standpoint epistemology." Needless to say, however, it is absurd to assume that there is the particular point of view which is non-European. A Japanese point of view and a Nigerian point of view, for instance, are both non-European but obviously different. Yet, the previous sentence itself is already problematic. For it is clearly not the case that we can specify the Japanese point of view or the Nigerian point of view (In the same way, it is impossible to specify "the European point of view"). No two Japanese people are the same in terms of gender, class, family, academic background, income, occupation, and a countless number of conceivable respects. ${ }^{15}$ Conceived in this way, it finally would turn out that it is only each individual who can have a standpoint distinguishable neatly from other standpoints. Even saying this may be unsatisfying inasmuch as it is, strictly speaking, not accurate to say that what you were yesterday, what you are at the moment, and what you will be tomorrow have exactly the same standpoint. It goes without saying that such a radical individualist or solipsistic line of thinking would not be the thesis many adherents of "standpoint epistemology" want to put forward (For it is simply a mistake to deny that Japanese people, for instance, do have a shared reality by virtue of being Japanese. ${ }^{16}$ But it is also a mistake in the opposite direction to try to reasonably and formalistically capture the "essence" penetrating the shared reality. There is no point reducing such an essence of the shared reality to a given set of principles and ideals).

One conclusion to be reached is that a "standpoint" can be defined in whatever ways according to arbitrary interests and concerns. In other words, it is a matter of various interests and concerns how individual standpoints are brought into focus.

We must not throw out the baby with the bath water, however. Despite my agreement with the charge of certain arbitrariness of the notion of standpoint, I have no problems with admitting that it has a relative but substantial effect. For our actual life is enabled by our capacity to draw on a diversity of standpoints not in theory but in practice. For instance, no one can catch a durationless instant of "now-time," but everyone lives relying on the notion of "now" by interpreting and understanding it arbitrarily but substantially—e.g., "now" can indicate "this moment," "these days," "this month," and even "this century" or longer. ${ }^{17}$ What is important to realize here is again that there is no point in striving to specify and enumerate individual "now-times" and thereby grasp something like the essential feature of now-time in an unambiguous way. ${ }^{18}$

\section{Concluding Remarks: Multiculturalism for a Better Future of Humanity}

I end this paper by urging that the centerpiece of discussions of multiculturalism has no necessary connection with either a strong absolutism or sheer relativism but instead provides a vital clue for considering the future of humanity.

A serious threat to the minimalist defence of something universal is that it is merely another way of arguing for a species of relativism, namely the possibility that an unbridgeable gap threatens to open between 
contending lines of rationality (and perspective). Alasdair MacIntyre, for example, asserts:

Fundamental disagreements about the character of rationality are bound to be peculiarly difficult to resolve. For already in initially proceeding in one way rather than another to approach the disputed questions, those who so proceed will have had to assume that these particular procedures are the ones which it is rational to follow. A certain degree of circularity is ineliminable. (MacIntyre 1988, 4)

It is evident that MacIntyre's elaboration of "the nature of tradition-constituted and tradition-constitutive enquiry” (MacIntyre 1988, 389) gives a nod to the idea of incommensurability. He argues:

If there are no neutral standards of rational justification independent of tradition, so that rival theories stemming from different traditions are each evaluated by reference to the standards internal to its own tradition, then it seems impossible to provide the requisite kind of comparison. Such rival theories will be incommensurable. (MacIntyre 1994, 150) ${ }^{19}$

However, as it has been implied, to exaggerate the extent to which competing bodies of knowledge and rationality are incommensurable has had a disastrous effect on the debate about multiculturalism (The most disastrous effect is to lend support to the view that such rival theories on the issues to do with multiculturalism are themselves incommensurable). There are two fatal flaws in the way the thesis of incommensurability is over-emphasized. First, it neglects the relative communicability of rival theories; second, it assumes a clear demarcation line that sets one standpoint (tradition, culture, society, and so on) apart from another.

The proper view to take is that it is, in principle, possible to communicate with people from "different backgrounds" in varying degrees and such an individual background never exists in isolation insofar as it has developed and will change through continuous borrowings and interchanges with other backgrounds. What makes possible such communication and dialogue is, à la John McDowell, the human capacity to be responsive to reasons, through which I want to approach the issues raised by multiculturalism. For responsiveness to reasons in extremely intricate ways is a distinguishable mark of humanity to the extent that what Robert Brandom calls "social practices of giving and asking for reasons" (Brandom 1994, XIV) is far beyond the physiological drive for survival. ${ }^{20}$ The reasons people attach to individual cases are of course diverse, but this does not entail a priori incommensurabilities precisely because the ability to be responsive to reasons is a desideratum to live as a human being, whoever and wherever she is, and it is prior to relative differences in terms of standpoints. ${ }^{21}$

Given the present "globalized" stage in human history, it seems more important than ever to take the implications of multiculturalism seriously. For we face a number of issues where high priority should be given not to particular groups of people but to the human community as a whole such as issues of environment and population. It is to be fully appreciated that the notion of standpoint has a relative but substantial effect without renouncing either Siegel's claim that the contextualist view is predicated upon something non-contextual or the contribution multiculturalist thinking has made, namely that "unfamiliar" standpoints turn us to the importance and urgency of the issues that have been absent from the "familiar" standpoints. This indicates that what is left with us is not the unattractive choice between competing and incommensurable bodies of knowledge and rationality but rather an option to increase the sophistication of a totality of knowledge and rationality for a better human future. The following remark of Harding's needs to be put in this context: "Some sciences are better if you want to get to the moon; others if you want to maintain sustainable environments" (Harding 2000, 255). ${ }^{22}$

Seeing them as contradictory is an obstacle to developing the maturity of the human community as a 
whole. The insights gained by a serious study of multiculturalism are all pertinent to such integral visions of the whole human community-e.g., the lines of research to be organized and their ethical responsibilities. These issues are surely complicated and intractable. And yet, a better future of humanity will not come without a deep appreciation of the implications of multiculturalism.

\section{Notes}

1. The widespread appeal of multiculturalism also stems from an (explicit or implicit) commitment to a Rawlsian version of liberalism. According to that, diversity and pluralism are essential features of liberal democratic states, and thus to accommodate and embrace such pluralism in designing institutions (e.g., education) is part of the project of achieving liberal legitimacy and stability. This topic is so large that it needs separate treatment. I will not, therefore, explore this Rawlsian version of liberalism in this paper.

2. The topics I point towards by invoking Siegel's discussion below are, of course, ones that are debated within the field of multicultural education and related disciplines such as women's studies and ethnic studies. See e.g., Seyla Benhabib 2002, especially Chapter 2. More importantly, to do full justice to Siegel, I must acknowledge that I sometimes use his stuff on critical thinking and rationality to address other topics such as multiculturalism and incommensurability. It should be stressed, thus, that I exploit his argument as a foil for my own views, and I definitely need to consult some other writings of his if I want to scrutinize his views. But this is not a central concern in this paper and I think our overall views are actually not very far apart at all.

3. Thus, as noted at note 2 above, while exploiting much of Siegel's argument to provide stimuli for thought, my main aim is not to open his views up to critical discussion. Rather my principal aim in this paper is, as it will become clear below, to give concrete contents to his formalistic argument, as it were, by focusing attention on the notion of standpoint. Despite his explicit recognition that "transcultural normative reach ... is not just a matter of formal logic, but of (contentful) reasons more generally" (Siegel 1999, 406), it may still be tempting to see that Siegel's argument highlights formalistic elements of the relevant issues.

4. Fallibilism is, Siegel defines, the thesis that "all claims are fallible and open to challenge, and no claims are certain" (Siegel 1997, 121).

5. It looks as if the primary emphasis of Siegel's conception of the aims of education is placed on the mere form of giving universal law by abstracting from a subject's particularities and contingencies. The form-matter distinction is not utterly wrong. However, it is to be appreciated that neither form nor matter exists in isolation.

6. He claims that "critical thinking is best seen as coextensive with rationality, and rationality is concerned with reasons" (Siegel 1988, 59). As mentioned earlier, I here conflate different issues by bringing critical thinking and rationality to our attention to talk about multiculturalism. These issues, however, have a certain connection in that what lies behind them is the issue of universal applicability of culturally and historically specific values and ideals.

7. The term "standpoint epistemology" is perhaps most often associated with the discussion of Sandra Harding. I appreciate the importance of her standpoint theory, but, as I hope will become clear, I use this term in a broad-brush sense in this paper.

8. It is to be remembered that Siegel insists that particular principles of reason assessment are specific to particular subjects.

9. Note, however, that what Siegel calls an underlying epistemology is not itself a standard or principle of reason assessment.

10. Siegel, contrary to the appearance of his vigorous vindication of Western Enlightenment thought, fully appreciates this point: "whether or not any of them (principles, values, and ideals that are conceived and embraced only in particular locales) enjoy legitimacy beyond the bounds of those locales is an independent matter" (Siegel 1999, 403).

11. Again, my aim is not to criticize Siegel's argument per se here. I exploit it to prompt fruitful speculation on the relevant issues.

12. Siegel himself is not committed to accepting this supposition.

13. It is widely recognized to be right up to a point. That is, there is a general agreement with regard to the insistence of standpoint epistemology that every standpoint confers epistemic advantages (and disadvantages) of particular sorts on the person occupying it.

14. Another slightly different way of making this point is that it is entirely unclear how much sense the idea of "all possible standpoints" makes. For "standpoints" come and go according to varied interests and concerns. In brief, it is impossible to exhaust available alternatives.

15. The key corollary here is that one person occupies a complex plurality of standpoints at one and the same time. This is why there is no disentangling one standpoint from another: "To suppose that a person can be adequately described by an epithet, such as 'romantic,' 'modern-minded,' or 'scientific,' is to suppose something disrespectful” (Russell 1975, 113); "it is difficult to talk about 'Chinese values' or 'Indian values' in a simplifying manner” (Nussbaum 1997, 130).

16. So, I agree that there are relatively stable platforms (which might be called shared realities) on which we lead our lives. But we should not be invited to identify them with ahistorical neutrality or Goldly perspectives. They gradually, though not immediately, grow and alter with our on-going interests, concerns, presuppositions, indifference, and so on and so forth.

17. In relation to the topic of "time," it may be worth mentioning the way time means different things in different cultures. For example, in English, a watch "runs;” in Spanish, a watch “walks;” in German, a watch "functions,” etc.. 
18. I am not claiming that Siegel puts his finger on such a barren enterprise when invoking the underlying unitary epistemology.

19. Thus he goes on to claim that: "As I argued in Whose Justice? Which Rationality?, the mistake is to suppose that if two or more rival bodies of theory have satisfied a condition of being formulated so as to be maximally open to refutation, each by the best standards available within its own tradition, then it is always possible that one of those rivals succeeds by its own standards in meeting all the critical challenges offered to it, while the other or others fail” (MacIntyre 1994, 150).

20. Compare this ability of the human species with that of other living beings. There is considerable research and debate on the issue of whether and to what extent other living beings, especially great apes, have the capacity to act and think beyond their biological conditions. Yet, it seems fairly uncontentious to me to say that the complexity of our ways of responding to reasons deserves to count as an important mark of humanity.

21. To equip the human infant to acquire this ability necessitates a process of education in the broadest sense. This is too substantial an issue to address here but, without question, it is of central importance in the study of education.

22. Harding is inclined to polarize the issues. For example, she asserts: "All of us have to be very clever about which knowledge system we use and when this can be a life-or-death matter” (Harding 2000, 255).

\section{Works Cited}

Benhabib, Seyla. The Claims of Culture Equality and Diversity in the Global Era. Princeton, NJ: Princeton University Press, 2002.

Brandom, Robert. Making It Explicit: Reasoning, Representing and Discursive Commitment. Cambridge, Mass: Harvard University Press, 1994.

Dhillon, Pradeep \& Haslstead, Mark. "Multicultural Education.” The Blackwell Guide to the Philosophy of Education. Eds. Nigel Blake, Paul Smeyers, Richard Smith, and Paul Standish. Oxford: Blackwell, 2003. 146-62.

Eagleton, Terry. Literary Theory: An Introduction. Oxford: Blackwell, 1983.

Fullinwider, Robert. "Multicultural Education.” A Companion to the Philosophy of Education. Ed. Randall Curren. Malden, Mass: Blackwell, 2003. 487-500.

Goldman, Alvin. "Education and Social Epistemology.” Philosophers on Education: Historical Perspectives. Ed. Amélie Rorty. NY: Routledge, 1998. 439-50.

Harding, Sandra. Whose Science? Whose Knowledge: Thinking from Women's Lives. Ithaca, NY: Cornell University Press, 1991.

Harding, Sandra. “Gender, Development, and Post-Enlightenment Philosophies of Science.” Decentering the Center: Philosophy for a Multicultural, Postcolonial, and Feminist World. Eds. Uma Narayan and Sandra Harding. Bloomington, IN: Indiana University Press, 2000. 240-61.

MacIntyre, Alasdair. Whose Justice? Which Rationality? London: Duckworth, 1988.

MacIntyre, Alasdair. "Nietzsche or Aristotle.” The American Philosopher: Conversations with Quine, Davidson, Putnam, Nozick, Danto, Rorty, Cavell, MacIntyre, and Kuhn. Ed. Giovanna Borradori. Chicago: University of Chicago Press, 1994. 137-52.

McDowell, John. The Engaged Intellect: Philosophical Essays. Cambridge, Mass: Harvard University Press, 2009.

Nussbaum, Martha. Cultivating Humanity: A Classical Defense of Reform in Liberal Education. Cambridge, Mass: Harvard University Press, 1997.

Russell, Bertrand. Mortals and Others: Bertrand Russell's American Essays, 1931-1935. Ed. Harry Ruja. London: Allen and Unwin, 1975.

Siegel, Harvey. Educating Reason: Rationality, Critical Thinking, and Education. NY: Philosophy of Education Research Library. Published by Routledge in association with Metheun, 1988.

---. Rationality Redeemed: Further Dialogues on an Educational Ideal. New York: Routledge, 1997.

---. “Knowledge, Truth and Education.” Education, Knowledge and Truth: Beyond the Postmodern Impasse. Routledge International Studies in the Philosophy of Education, 4th. Ed. David Carr. London: Routledge, 1998. 19-36.

---. "Multiculturalism and the Possibility of Transcultural Educational and Philosophical Ideals.” Philosophy 74.3 (1999): $387-409$.

---. "Cultivating Reason.” A Companion to the Philosophy of Education. Ed. Randall Curren. Malden, Mass: Blackwell, 2003. 305-19.

---. “Epistemological Diversity and Educational Research: Much Ado About Nothing Much?” Educational Researcher 35.2 (2006): 3-12.

---. "Multiculturalism and Rationality.” Theory and Research in Education 5.2 (2007): 203-23.

---. "Autonomy, Critical Thinking and the Wittgensteinian Legacy: Reflections on Christopher Winch, Education, Autonomy and Critical Thinking.” Journal of Philosophy of Education 42.1 (2008): 165-84. 